\title{
Leitura do gênero homepage: uma proposta didática
}

\author{
Bruno Ciavolella \\ Universidade Estadual de Maringá \\ Marilurdes Zanini \\ Universidade Estadual de Maringá
}

\begin{abstract}
Resumo
Subsidiados pelos Novos Estudos dos Letramentos e na concepção de leitura dialógica, inspirada no Círculo de Bakhtin, este artigo objetiva apresentar uma proposta didática com atividades de leitura do gênero homepage que articule os elementos contextuais da situação de interação com a constituição desse gênero, tanto nos aspectos pragmáticos quanto nos formais.
\end{abstract}

Palavras Chave: leitura, letramentos, homepage

\begin{abstract}
Based on the New Literacy Studies and on the concept of dialogic reading, from the Bakhtin Circle, this article presents a proposal of reading activities for the genre homepage. The proposal links the contextual elements of the situation of interaction with the discourse characteristics, in both the pragmatic and the formal aspects of this genre.
\end{abstract}

Keywords: reading, literacies, homepage.

\section{INTRODUÇÃO}

Já são muitos os elos constituintes da cadeia discursiva que desperta o interesse sobre a prática e o ensino da leitura nas mais diversas esferas de atividade humana, principalmente nas instituições legitimadas, tais como os ambientes escolar e acadêmico. Nesse diálogo, diferentes vozes se aproximam no ensejo de promover um ensino-aprendizagem significativo, capaz de oferecer condições para o desenvolvimento do aluno como leitor pleno, ou seja, construtor de sentidos e produtor consciente de novas palavras, ou contrapalavras no sentido bakhtiniano.

Nesse contexto, este artigo visa a contribuir com esse diálogo apresentando uma proposta de atividades de leitura com o gênero digital homepage. Nosso objetivo, com as atividades, é colaborar para a ampliação e o desenvolvimento das capacidades e dos conhecimentos necessários nas práticas de multiletramentos que ocorrem no ciberespaço. 
Para tanto, buscamos aparato teórico na concepção dialógica de linguagem, discutida pelo Círculo de Bakhtin, que nos dá sustentação para compreendermos a leitura como uma atividade dialógica. Buscamos, todavia, enfatizar as particularidades dessa perspectiva, inclusive para pensar as questões de leitura dos hipertextos, aspecto essencial, tendo em vista as práticas de interação no ciberespaço, caracterizadas pelas múltiplas linguagens - verbais e não verbais. Isso nos faz, pois, perceber que, para o desenvolvimento de um leitor pleno, o professor na sala de aula deve mediar o acesso dos alunos a essas novas práticas de interação.

\section{A CONCEPÇÃO DIALÓGICA DE LEITURA}

Considerar a linguagem na sua dimensão ininterrupta é assegurar o processo dialógico inerente à sua constituição. Essa premissa, disseminada nos estudos do Círculo de Bakhtin, conduz-nos à reflexão da leitura como um processo dialógico que envolve a construção de sentido do texto e a constituição dos sujeitos que participam das situações de interação. A perspectiva pela qual vemos a leitura neste artigo a situa na esfera escolar, com o objetivo de desenvolver as capacidades de leitura necessárias para a participação consciente do aluno nas práticas de linguagem, verbais e não verbais, nos ambientes convencionais e virtuais. Essa concepção traz para o centro das reflexões o interesse pelo funcionamento real da linguagem, compreendida como matéria histórico-social, visto que a sua natureza é constitutivamente dialógica.

O Círculo compreende, então, a linguagem na sua essência, como substância plena e, ao mesmo tempo, incompleta, ou seja, propriedade viva e constituinte das relações humanas. Essa natureza dinâmica da linguagem amplia a concepção de língua: além de ser sistema, ela é reconhecida como prática social, caracterizada pelo dialogismo, o que a faz um signo não só linguístico, mas, sobretudo ideológico.

\footnotetext{
Na realidade, não são palavras o que pronunciamos ou escutamos, mas verdades ou mentiras, coisas boas ou más, importantes ou triviais, agradáveis ou desagradáveis, etc. A palavra está sempre carregada de um conteúdo ou de um sentido ideológico ou vivencial. É assim que compreendemos as palavras e somente reagimos àquelas que despertam em nós ressonâncias ideológicas ou concernentes à vida. (BAKHTIN/VOLOSHINOV, 2006, p. 96, destaque do autor)
}

A linguagem desenvolve-se, desse modo, por meio da interação verbal, prática social de uso, que emerge de necessidades específicas, tornando-se significativa no estabelecimento e, também, no entrelaçamento dos diversos tipos de relações 
construídas na sociedade. Devido ao dialogismo, em cada situação de enunciação, encontram-se ressonâncias de diferentes dizeres constituídos em outras épocas e contextos, ao mesmo tempo em que passa também a servir de referência para as próximas manifestações de uso da linguagem.

Para Bakhtin, toda situação de enunciação emerge de uma necessidade social efetiva, o que garante o traço de finalidade inerente a toda interação. Como reguladores dessa situação, encontram-se dois fatores: o contexto imediato - o local, a prática social, a cultura, os interlocutores, o gênero discursivo - e o horizonte social e dialógico mais amplo, referente aos discursos que perpassam a prática realizada. A natureza mutável e dialética da linguagem proporciona modelos relativamente estáveis de interagir - os gêneros discursivos. Neles, os enunciados, mediadores do processo interativo, configuram-se em atendimentos ao contexto social e cultural e às demandas das práticas sociais para as quais foram planejados. Por isso, para Bakhtin, existem tantos e tão variados gêneros discursivos na mesma proporção das esferas de atividade humana.

A linguagem é dialógica porque também é responsiva. Por ter uma finalidade e ser uma prática social definida, a interação verbal configura-se como uma forma de ação no mundo, despertando sempre reação, ou melhor, dizendo, atitudes responsivas.

Bakhtin/Voloshinov (2006) caracterizam a responsividade como aspecto intrínseco à linguagem, asseverando que toda "enunciação, mesmo na forma imobilizada da escrita, é uma resposta a alguma coisa e é construída como tal [...] Uma inscrição, como toda enunciação monológica, é produzida para ser compreendida [...]" (p. 99).

Nesse sentido, começamos a refletir sobre o processo de leitura, conforme o Círculo concebe a compreensão, isto é, como uma atividade inerente à necessidade de resposta que a natureza da linguagem instaura. Isso nos leva, em princípio, a afirmar que, para a concepção dialógica de linguagem, ler é responder. $\mathrm{O}$ ato da escuta e o da leitura, de modo geral, nada mais são do que atividades constitutivas do funcionamento da linguagem. São os elos que completam a necessidade de compreensão que todo texto apresenta.

Por sua vez, como a linguagem não é, apenas, um instrumento de comunicação, mas, sim, uma prática social de interação, a leitura na esfera escolar, conforme assinala Marcuschi (2008, p. 230), extrapola os limites linguísticos e cognitivos, configurando-se em uma forma de agir sobre o mundo: "Compreender não é uma ação apenas linguística ou cognitiva. É muito mais uma forma de agir sobre o mundo na relação com o outro 
dentro de uma cultura e uma sociedade". Trabalhar com leitura, em sala de aula, implica constituir esse trabalho sob uma forma de agir no mundo.

Geraldi (2007, p. 42), amparado também na perspectiva bakhtiniana, afirma que a leitura é uma oferta de contrapalavra, porque a compreensão resulta do choque entre aquilo que está no texto e a resposta, a contrapalavra construída pelo leitor: “[...] a compreensão resulta não do reconhecimento da palavra aí impressa, aí ouvida, mas do encontro entre palavra e suas contrapalavras [...]”.

Nessa perspectiva, tal como enfatiza Bakhtin (1999), a compreensão não requer, apenas, o reconhecimento do código, do signo linguístico, mas, sim e também, as orientações de sentido em uma situação concreta de interação verbal. Assim, aceitamos que "a compreensão não é uma espécie de decodificação, como se nossa atividade de decodificação fosse uma simples depreensão de sentidos a partir de elementos postos no texto" (MARCUSCHI: 2008, p.231). O ato de compreender é, pois, uma atividade complexa que envolve uma série de conhecimentos, competências e habilidades, tanto no âmbito linguístico quanto cognitivo. Esses conhecimentos, competências e habilidades são, entretanto, determinados pelos elementos que compõem cada situação de interação.

Dessa forma, o processo de compreensão não envolve, apenas, a consideração dos enunciados, mas também a situação de enunciação. Por isso, assumimos, neste texto, uma concepção dialógica de leitura, segundo a qual a compreensão é determinada pela situação única de uso da linguagem e, por isso, os sentidos construídos são, também únicos. Nas palavras literais de Bakhtin/Voloshinov (2006, p. 94),

[...] o essencial na tarefa de decodificação (compreensão) não consiste em reconhecer a forma utilizada, mas compreendê-la num contexto concreto preciso, compreender sua significação numa enunciação particular .

Isso implica, por conseguinte, que as atividades de leitura no espaço e na situação de interação instaurada na sala de aula devem considerar, sempre, o contexto dos textos: a situação de interação imediata bem como o horizonte social e ideológico dos seus participantes.

No que se refere à situação imediata, não podemos deixar de levar em conta estes elementos: a) a prática social - ou seja, perceber a necessidade social à qual linguagem atende e o lugar de valor dessa necessidade para tal prática; b) o local - o contexto que envolve os textos e as características do local físico em que se dá a interação ou ocorre a circulação desses textos; c) os objetivos - os propósitos aos quais 
aquela prática de linguagem procura satisfazer; d) a materialização textual - o leitor aciona conhecimentos acumulados - ou é mediado para acessá-los - a respeito do gênero discursivo em pauta, considerando os seus eixos estruturadores: o tema, a construção composicional e o estilo; e) os parceiros da interação - autor e leitor principalmente no que se refere ao papel social de cada um deles.

Por outro lado, no que consiste o horizonte social mais amplo, parece ser necessário que se busque articular a forma como os elementos da situação imediata foram determinados pela esfera de atividade humana em que estão inseridos e, consequentemente, pela formação ideológica que perpassa essa atividade.

Sob essa concepção, a leitura abarca uma situação do caráter enunciativo em que se imbricam os discursos que se constroem pela e na interação por meio da linguagem, os quais, por sua vez, revelam modos diferentes de se conceber aquilo que existe no mundo, visto que, segundo Bakhtin (1999), todo signo é ideológico e, portanto, é na palavra, signo por excelência, que os confrontos de poder, as lutas de classes e as identidades são construídos.

Assim, se ler é compreender e compreender é uma resposta, ao se considerar a representação dos sujeitos em cada situação de enunciação em que os processos interativos foram estabelecidos, a atividade de leitura se constitui como uma oferta de contrapalavras:

um leitor que não oferece às palavras lidas as suas contrapalavras, recusa a experiência da leitura. É preciso vir carregado de palavras para o diálogo com o texto. E estas palavras que carregamos multiplicam as possibilidades de compreensão do texto (e do mundo) porque são palavras que, sendo nossas, são de outros, e estão dispostas a receber, hospedar e modificar-se face às novas palavras que o texto traz (GERALDI, 2007, p. 43).

Nas situações de interação no espaço do ciberespaço, a oferta de contrapalavras demanda considerar os múltiplos letramentos e, por isso, as competências e habilidades necessárias para a leitura de hipertextos.

\section{Leitura de hipertextos por meio da homepage}

Com o advento da Internet, novas possibilidades enunciativas se potencializaram, e, por conseguinte, diferentes competências e habilidades para a leitura e produção de textos passaram a ser requeridas. Nesse cenário, o hipertexto destaca-se por ser a modalidade textual que atende às necessidades interacionais dos eventos de letramento no ciberespaço. A escola, como agência de letramento, emerge como o 
espaço ideal para ofertar aos alunos instrumentos que possam auxiliá-los a se tornarem construtores de contrapalavras nas práticas de letramento da rede. Nesse sentido, acreditamos ser preciso discutir, mesmo que brevemente, as particularidades do hipertexto e as suas implicações na prática de leitura.

Entendemos o hipertexto como um enunciado cuja materialização se assemelha ao texto impresso, mas com algumas particularidades potencializadas pelas tecnologias digitais. Por isso, neste texto, reportamo-nos ao hipertexto, pensando em sua realização na rede, sem desconsiderar o fato de que sua natureza e sua existência não se esgotam no seu local de construção, nem, tampouco, são exclusivas desse que é o espaço virtual ${ }^{1}$.

A escritura hipertextual, segundo Marcuschi (2001, p. 86), caracteriza-se pela não-linearidade, ou seja, “como um processo de escritura/leitura eletrônica multilinearizado, multissequencial e indeterminado, realizado em um novo espaço de escrita". Como uma trilha, o hipertexto pode ofertar diversos caminhos para serem escolhidos pelo leitor. Gomes (2011, p. 25), nesse sentido, afirma que "os links são os elementos centrais do hipertexto. Sem eles, o hipertexto é apenas texto. Há diferentes tipos de links que, conforme o local onde são postos e as ligações que promovem, modificam, ampliam, induzem ou restringem sentidos".

Outro aspecto peculiar nessa prática textual é a multimodalidade, já que é o "traço que se define pela possibilidade de estabelecer conexão simultânea entre a linguagem verbal e a não verbal (imagens, animações, som) de maneira integrativa, graças aos recursos de hipermídia" (KOMESU, 2005, p. 101). Em outras palavras, conforme assinala Gomes (2007), a multimodalidade caracteriza-se pela presença de diversos modos de representação em um texto, sendo este composto, além da linguagem verbal escrita e sonora, também pela linguagem não verbal, tais como as imagens, as animações, os gestos, etc. A multimodalidade que se destaca nos hipertextos requer, na análise textual, que todos esses elementos de representação sejam considerados. Nas palavras do estudioso: "[t]rata-se, portanto, de compreender o sentido como o resultado da inter-relação entre as linguagens, como um processo de ressemiotização ou ressignifcação" (GOMES, 2007, p. 62). Isso nos faz compreender que, ao escrever um hipertexto, o produtor aciona não somente seus conhecimentos sintáticos, semânticos e

${ }^{1}$ Existem vários estudos que colocam em discussão a natureza do hipertexto, tais como os de Marcuschi (2001), de Xavier (2002), de Gomes (2007), de Ribeiro (2008). 
morfológicos, uma vez que o espaço onde o produz requer rapidez e também diferentes linguagens para ser utilizadas na interação.

Assim sendo, o produtor aponta caminhos múltiplos que extrapolam os limites de um texto impresso: os links são pistas que desviam o leitor dos caminhos previsíveis nas construções lineares ancoradas em aspectos e conhecimentos gramaticais e lexicais. Ao fazer uso de um link, o produtor indica a rota para outro espaço de interação. Ocorre nesse momento e nessa ação uma confluência de múltiplas linguagens e vozes. Essa confluência passa a acontecer graças à convergência das mídias, possibilitadas pelas tecnologias digitais, o que confere aos textos novas possibilidades interativas.

A escrita que, durante muito tempo, detinha quase que exclusivamente o status do saber, agora convive com a cultura da convergência, na qual predominam as práticas multiletradas. Com isso, novos e desconhecidos gêneros discursivos ou textuais surgem com a mesma rapidez com que a interação se dá no espaço digital, virtual ou ciberespaço. Uns se fortalecem e permitem serem nominados, dentre eles, a homepage.

\section{Homepage: gênero discursivo de natureza hipertextual}

A homepage é um exemplo de gênero que, aqui, denominamos de discursivodigital, graças à sua natureza hipertextual, à sua estrutura tão nova quanto desconhecida, ao espaço onde se materializa - o digital. Só assim, cremos que podemos colocá-lo no rol de gêneros discursivos socialmente já reconhecidos.

A produção e a leitura desse gênero procuram considerar a natureza enunciativa do ciberespaço tanto no que se refere às possibilidades enunciativas agregadas às tecnologias digitais quanto, também, a reconhecer essas práticas como configuradas por um novo modo cultural, a cibercultura, caracterizada pela pluralidade e pela hibridização de linguagens e, por conseguinte, de ideias.

As duas funções principais da homepage, segundo Bezerra (2007), apoiado em Askehave e Nielsen (2004), são: a) introduzir o conteúdo geral do site, ou seja, situar o usuário a respeito dos serviços, tais como orientações que naquele endereço são oferecidas; b) funcionar como um gênero introdutório que anuncia diversas possibilidades de informações que ali podem ser acessadas. Esse caráter introdutório, de acordo com o estudioso, assemelha-se à primeira capa de um jornal, já que ambas têm por objetivo traçar um panorama do conteúdo disponível para leitura, no ambiente virtual e no periódico, respectivamente. 
Bezerra explica os dois propósitos comunicativos que, tradicionalmente, esse gênero digital apresenta: um primário e o outro secundário.

[...] o propósito comunicativo primário da homepage no modo de leitura seria introduzir/apresentar o site. Outros propósitos, no entanto, podem estar explícita ou implicitamente presentes: criar ou consolidar a imagem do proprietário do site; apresentar notícias (locais ou não) (BEZERRA, 2007, p. 07).

A importância dos propósitos comunicativos de um evento de letramento reside no fato de que eles direcionam o processo de construção de sentido. Oferecer condições para que, no momento da leitura de uma homepage, seja interpretada qual a imagem que o criador do site procura delinear ou descrever é oferecer aos alunos oportunidades para que se comportem criticamente nas práticas de linguagem que acontecem no mundo digital. Sendo assim, para que isso aconteça, deve-se procurar mediar o acesso dos estudantes ao modo de construção multimodal desse gênero. Essa mediação auxilia na formulação da imagem que o autor deseja apresentar. Melhor dizendo, é preciso que se explorem os elementos constitutivos do hipertexto, permitindo-lhe observar e compreender a forma como esses elementos estão adaptados, tendo em vista os objetivos a seres atingidos. Com isso, os estudantes passarão a refletir sobre a funcionalidade da linguagem quanto aos seus aspectos verbais e não-verbais, prática fundamental para o desenvolvimento de sua formação como produtor e, principalmente aqui, como leitor de hipertextos.

\section{PROPOSTA DIDÁTICA DE LEITURA DA HOMEPAGE}

É um grande desafio elaborar propostas didáticas, uma vez que, além dos fatores específicos relacionados ao objeto de conhecimento tratado, necessariamente precisamos considerar a sua efetivação e eficácia. Por isso, é preciso reconhecer os alunos como sujeitos que participarão dessa prática, articulando-a, sempre, com os objetivos determinados para cada ambiente de ensino. Nesse sentido, a proposta aqui apresentada não assume o caráter de modelo, mas, sim, expõe-se como uma possibilidade para se levar o gênero homepage como um espaço possível de interação entre o produtor e o leitor para a construção de sentidos nas práticas de leitura nas aulas de língua materna.

Neste trabalho, o foco não está em apresentar um software, um aplicativo, um objeto de aprendizagem virtual, mas, sim, em propor algumas atividades pedagógicas que contribuam para a ampliação e desenvolvimento das capacidades e habilidades 
necessárias para a leitura de gêneros discursivos, dentre os quais, a homepage. Isso implica não somente uma série de considerações de ordem cognitiva, mas, principalmente, das condições enunciativas. Assumindo a concepção dialógica de leitura, reconhecemos que as capacidades de leitura, juntas, são fundamentais para a formação de um construtor de contrapalavras.

Com as atividades que apresentamos, não é nosso intuito, apenas, que os alunos percebam e reconheçam a hipertextualidade e a multimodalidade que constituem esse gênero, mas, sim, é contribuir para que possam ter atitudes responsivas, de forma a produzirem e assumirem suas próprias palavras.

Elaborada para ser trabalhada nas séries finais do ensino fundamental, nossa proposta consiste em atividades de leitura a respeito de três homepages pertencentes às esferas de atividades humanas diferentes. São elas: a página inicial da novela Malhação, o site do Governo do Estado do Paraná e também o portal de conteúdos UOL. Tendo como premissa que a organização de toda situação de interação se dá tanto pelo contexto imediato quanto pelo horizonte social mais amplo, as atividades em que se desdobra a nossa proposta apresentam-se em três fases: homeconversa; homepage e home-estudo.

A homeconversa (quadro 1) - atividades introdutórias de leitura - tem por objetivo introduzir a prática de leitura. Por meio de uma discussão oral, a atividade motiva os alunos a discutirem sobre o contato que eles têm com a homepage, já que é um texto recorrente no ciberespaço. Com isso, buscamos resgatar os seus conhecimentos, aproximando-os da atividade a ser realizada.

As perguntas, de modo simples, iniciam o processo de reflexão a respeito dessa prática de produção textual. Isso se deve, porque nosso propósito com as atividades não é operacionalizar os estudantes para lerem esse gênero discursivo, mas, sim, contribuir para a formação de sujeitos que usam, mas, sobretudo, refletem a respeito da linguagem.

\section{HOMECONVERSA}

- A maioria dos sites possui uma página inicial, uma homepage. Quais são as características das homepages dos sites em que vocês acessam?

- Todos os sites possuem homepages?

Quadro 1: Primeira fase das atividades de leitura 
Por sua vez, a segunda fase das atividades, Homepage (quadro 2), é o momento destinado ao acesso às páginas. Ressaltamos a necessidade de se explorar todas as possibilidades que as homepages oferecem, já que, por ser um gênero introdutório e da natureza hipertextual, elas oferecem diversas possibilidades de leitura.

\section{Homepage}

- Naveguem pelos seguintes sites: www.globo.com/malhação

$\underline{\text { www.uol.com.br }}$

www.parana.gov.br

Quadro 2: Segunda fase das atividades de leitura

A terceira fase da atividade, home-estudo (quadros 3-5), como o próprio nome salienta, consiste no estudo sobre a prática de interação verbal, mediada por essas homepages. Essa fase se divide em três momentos. As atividades visam a abarcar a totalidade dos elementos constitutivos dessas situações de interação. Neste texto, apresentamos apenas algumas das atividades que compõem cada momento desta etapa da proposta.

\section{HOME-ESTUdO}

- Vamos construir uma tabela com informações referentes às situações contextuais que envolvem as homepages que estamos estudando. Esta tabela será preenchida pelas respostas às seguintes questões:

$>$ As homepages, apesar de estarem no ciberespaço, situam-se em contextos diferentes, uma vez que atendem às necessidades comunicativas de esferas sociais distintas. Para cada homepage, cite algumas ações que as pessoas fazem ao acessar o site. Por exemplo, as pessoas procuram a homepage da novela para ler os resumos dos capítulos.

$>$ Tendo em vista as ações colocadas na questão, aponte quais os interesses que esses sites despertam ao público. Por exemplo, no site do Governo do Estado do Paraná, os interesses são políticos, informacionais etc.

$>$ Quais são os interlocutores, isto é, de quem é o site e qual é o público presumido pelo produtor. Encontrem, nas homepages, elementos multimodais (escrita, sons, imagens) que justifiquem e comprovem as suas respostas em cada homepage.

Quadro 3: Primeira etapa da terceira fase das atividades de leitura

Nesta primeira etapa da terceira fase, enfatizamos as características contextuais que envolvem cada homepage e, consequentemente, isso acontece por meio da 
mediação do professor que permite aos alunos irem construindo conhecimentos sobre esse gênero. Com essas questões e com o acesso ao conhecimento do gênero, acreditamos ser possível evidenciar os usos sociais da linguagem e sua adequação a cada necessidade enunciativa.

Merecem destaque, na segunda etapa, atividades que discutam as características do gênero discursivo em pauta nos seus aspectos temáticos, composicionais e estilísticos como sugerimos a seguir:

- Quais elementos multimodais (escrita, imagens, vídeos, músicas, links e demais recursos da $w e b)$ compõem cada uma das homepages? Quais desses elementos aparecem com maior ou menor ênfase em cada uma das homepages? As homepages seriam as mesmas sem alguns desses elementos textuais?

- Observem quais os caminhos que os links disponíveis em cada homepage sugerem e anotem aqueles que considerarem principais. Verifiquem tantos os links que conduzem para páginas do próprio site quanto aqueles que conduzem o leitor a páginas de outros sites.

- Dividam-se em três grupos. Cada um fará a atividade relacionada a uma das três homepages. No final, cada grupo mostrará o resultado da atividade para os demais colegas. Juntos, vocês farão um trabalho de análise que terá como objetivo responder a seguinte questão: O modo como os elementos multimodais foram empregados adéqua-se ao contexto e aos propósitos comunicativos de cada homepage? Para responder a esta questão, faça uma análise do uso de cada elemento textual multimodal (o texto escrito, as imagens (estáticas ou em movimento), os sons, os flashs). Relacionando esses elementos com os objetivos propostos em cada homepage.

Quadro 4: Segunda etapa da terceira fase das atividade de leitura

Com estas atividades objetivamos refletir sobre as possibilidades de significar, construir sentidos, utilizando-se das múltiplas linguagens que constituem o gênero homepage. Buscamos não somente salientar a multimodalidade de linguagens que se imbricam nesse hipertexto, mas sim analisar como os elementos multimodais articulamse com os propósitos comunicativos de cada homepage, de forma a permitir a interpretação das posições discursivas, das identidades a respeito daquilo que é exposto. Já que se trata de um texto de natureza hipertextual, a proposta também aborda como o texto se relaciona com os outros, por meio dos caminhos propostos pelos links. Procuramos, assim, enfatizar que o dialogismo, inerente à linguagem, acontece não só espontaneamente, mas também de forma planejada. Os caminhos que os links sugerem na homepage revelam interesses por parte do produtor. Por meio dessas atividades, abordamos conhecimentos sobre a estrutura composicional desse gênero, relacionando-a com os propósitos comunicativos da homepage. Essa abordagem e a discussão que ela permite são, a nosso ver, essenciais nessa prática de construção de sentido do hipertexto. 
Por fim, tendo em vista atingir também a dimensão ideológica que perpassa as práticas de linguagem, elaboramos também algumas atividades com o intuito de discutir a imagem que o produtor faz dos seus interlocutores e também que imagem do produtor se revela nessas páginas, conforme sugerimos a seguir:

- A partir das atividades de leitura da homepage, reflita sobre como o produtor do site concebe seus interlocutores. Para isso, analise o modo como os elementos multimodais foram empregados. Quais os conhecimentos necessários para interagir no site.

- Colocando-se no papel social de leitor dessas homepages, como você avalia essas páginas no que se refere ao cumprimento dos propósitos comunicativos?

Quadro 5: Terceira etapa da terceira fase das atividades de leitura

O modo como os elementos multimodais foram organizados na página, a forma como os interlocutores são identificados, os conhecimentos necessários para a interação no site são indícios que ajudam a construir a representação que o autor do site tem de seus leitores e também da imagem que o site representa. Com esses conhecimentos, os estudantes terão informações mais sólidas que os ajudarão na construção de suas contrapalavras, de suas atitudes responsivas.

Apostando na interação pelas múltiplas linguagens, significativas para motivar o posicionamento dos sujeitos, estimulamos os estudantes a manifestarem sua opinião, construindo contrapalavras, as quais garantam o caráter dialógico da linguagem, prática social sempre prenhe de resposta.

\section{CONSIDERAÇÕES FINAIS}

A atividade aqui proposta procura ressaltar o dialogismo como característica singular para a construção de sentidos. Procuramos no gênero homepage encontrar os elementos de uma prática social que leve os estudantes a refletirem sobre a significação de cada um deles na constituição desse gênero. Nessa trajetória, desejamos que os estudantes compreendam como a configuração desse gênero discursivo se relaciona com os aspectos sociais e permite a inter-relação da vida com a linguagem.

Como a proposta de ensino-aprendizagem de leitura aborda a homepage, enfatizase a necessidade de se reconhecerem as potencialidades comunicativas acrescentadas pelas tecnologias digitais. Por isso, as atividades visam a contemplar as competências e as habilidades necessárias para as práticas de letramentos que envolvem diferentes linguagens. 
Acreditamos que, ao se privilegiar o caráter dialógico da linguagem nas atividades de leitura em sala de aula, tem-se mais possibilidade de despertar nos estudantes atitudes responsivas por meio de atividades que os estimulem à construção de novos sentidos e, por conseguinte, de novas contrapalavras.

\section{REFERÊNCIAS}

BAKHTIN, M; VOLISHINOV, V.(2006). Marxismo e filosofia da linguagem. 12. ed. São Paulo: Hucitec.

BAKHTIN, M. (1999). Estética da criação verbal. 2. ed. São Paulo: Martins Fontes. Traduzido por Maria Ermantina Galvão G. Pereira.

BEZERRA, B. G. (2007). Gêneros introdutórios mediados pela web: o caso da homepage. Hipertextus revista digital (UFPE), v. 1, p. 1-10.

GERALDI, J. W. (1997). Portos de Passagem.4.ed. São Paulo: Martins Fontes.

(2007) Leitura: uma oferta de contrapalavras. In: GECE - Grupo de Estudos dos Gêneros do Discurso. O Espelho de Bakhtin. São Carlos: Pedro e João Editores, p. $39-46$.

GOMES, L. F.(2007). Hipertextos multimodais: o percurso de apropriação de uma modalidade com fins pedagógicos. 2007. Tese de doutorado, UNICAMP.

$$
\text { . (2011). Hipertexto no cotidiano escolar. São Paulo:Cortez, } 2011 .
$$

KOMESU, F. (2005). Pensar em hipertexto. In: ARAÚJO, J.C; BIASI-RODRIGUES, B. Interação na Internet: novas formas de usar a linguagem. Rio de Janeiro: Lucerna, 2005, p. 87-108.

MARCUSCHI, L. A. (2001). O Hipertexto como um novo espaço de escrita em sala de aula. Linguagem \& Ensino, Pelotas - RS, v. 4, n. 1, p. 79-112.

Parábola.

(2008). Produção textual, análise de gêneros e compreensão. São Paulo:

RIBEIRO, A. E. (2008). Navegar lendo, ler navegando: aspectos do letramento digital e da leitura de jornais. Tese de doutorado, Universidade Federal de Minas Gerais.

XAVIER, A. C.S. (2002). Hipertexto na sociedade da Informação: a construção do modo de enunciação digital. Tese de doutorado, UNICAMP.

\section{OS AUTORES}

Bruno Ciavolella é graduado em Letras pela Universidade Estadual de Maringá e acadêmico do curso de Mestrado em Letras pela mesma instituição.

E-mail: brunociavolella@hotmail.com 
Marilurdes Zanini é pós-doutora pela Unicamp e professora do programa de pósgraduação em Letras da Universidade Estadual de Maringá.

E-mail: marilurdes.zanini@hotmail.com 